\title{
The role of clay minerals in durability of rocks observations on basaltic rocks
}

\author{
R.A. Kühnel ${ }^{\text {a, } *}$, S.J. Van der Gaast ${ }^{\text {b }}$, J. Brych $(\dagger)^{\text {c }}$, G.J. Laan ${ }^{\text {, }}$, \\ H. Kulnig ${ }^{\mathrm{e}}$ \\ ${ }^{a}$ International Institute for Aerospace Survey and Earth Sciences, Kanaalweg 3, 2628 EB Delft, \\ The Netherlands \\ ${ }^{\mathrm{b}}$ Netherlands Institute for Sea Research (NIOZ), Texel, The Netherlands \\ c Technical University Mons, Mons, Belgium \\ ${ }^{d}$ Road and Hydraulic Engineering Division, Delft, The Netherlands \\ ' Basalt A.G., Linz a/R, Germany
}

Received 20 January 1994; accepted after revision 24 August 1994

\begin{abstract}
Knowledge of the durability of rocks, regardless of their size or shape, is essential for determining the safety and lifetime of structures and monuments. Hydraulic structures in particular require a high probability of survival of at least 100 years and monuments closer to a millennium. The degradation of a rock is often caused by clay minerals which are present in the rock from its origin and/or which have been formed in the rock in its geological history on account of the less stable rock constituents. In their fresh state during quarrying and mining it is difficult to recognize tendencies toward degradation and decay in rocks with time. For the selection of high quality construction materials (basaltic rocks) a series of new testing techniques has been developed in which the focus is on the role of clay minerals. This paper deals with occurrences, neoformation and behaviour of clay minerals which contribute to an early recognition of tendencies of rock decay.
\end{abstract}

\section{Geological history}

The durability of rocks for construction purposes is one of the essential prerequisites for all users. Generally speaking, rock quality is defined in terms of physical and chemical properties; rock behaviour is defined over time and often under changing conditions. Immediately after mining a rock may show satisfactory mechanical properties, though in time the

This paper was presented at the 10th International Clay Conference of AIPEA in Adelaide, 23 July 1993.

* Corresponding author. 
process of degradation may proceed to a point of fast rock decay. This is the case for some basalts frequently used for road construction and waterworks. From that point of view, the durability of a rock would be a prevailing criterion in quality requirements.

From the petrological point of view, the quality of basaltic rocks is a complex function of mechanical and chemical stability of the rock-forming constituents, including the often overlooked minor ones. The quality of basalt in any geological formation varies from place to place due to the heterogeneity of the rock itself and mainly due to the heterogeneity of conditions in which the rock was formed and cooled down. The scale of such variability is a matter of metres. Degraded zones (hydrothermally altered and/or weathered) are usually related to the tectonic faults, interfaces with other geological formations and to the surface of the volcanic bodies. Water plays an important role in the rock deterioration; basalts which are formed in a wet environment usually show higher heterogeneity and lesser durability.

All lava contain some minor quantity of water. During the rock formation, additional water uptake from the wet environment favours reactions of less stable constituents. Uptaken water penetrates the rock along fractures and voids so that beside the surface weathering, "hydrothermally altered zones" occur along porous and fractured segments of the volcanic rock bodies. The rocks from such zones exhibit generally lower durability. In such zones are the optimum conditions for the neoformation of clay minerals.

\section{Objectives}

The guarantee of rock quality for construction purposes is the prior objective of this research. Because of the multipurpose application of basalt in civil engineering and industry, the ranking of rocks from different sources is necessary for optimum utilization. The third objective is the recognition of long term behaviour. In rocks being exposed to different environments many reactions proceed which lead to mineralogical, chemical and physical changes. Subsequently, mechanical properties change. The rate of these changes is different for different rocks and is not constant with time, as shown by Kühnel and Brych (1994); see Fig. 1. For recognition of the long-term rock behaviour it is necessary to develop testing techniques which could help in quantification of the durability for civil engineering applications.

\section{Clay minerals in basaltic rocks}

Clay minerals occur in any so-called "fresh" basaltic rocks, as recently reported by Bain and Russell (1980, 1981), Bain et al. (1980), Cole and Sandy (1980), Eggleton et al. (1987) and many others. Clay minerals are present in the rocks in minor or in significant quantities. Clay minerals were formed in different periods of the long geological history. The first clay minerals in basalts were formed in the early post-volcanic period after intrusion and/or deposition (see Kühnel and Van der Gaast, 1989). Each lava contains some water which becomes either incorporated into some silicates (e.g. in amphiboles, micas and in glass) or as steam causes hydration of less stable constituents such as olivine, glass, feldspahtoides, etc. In such a way chlorites, serpentine, smectites and goethite are formed. An 


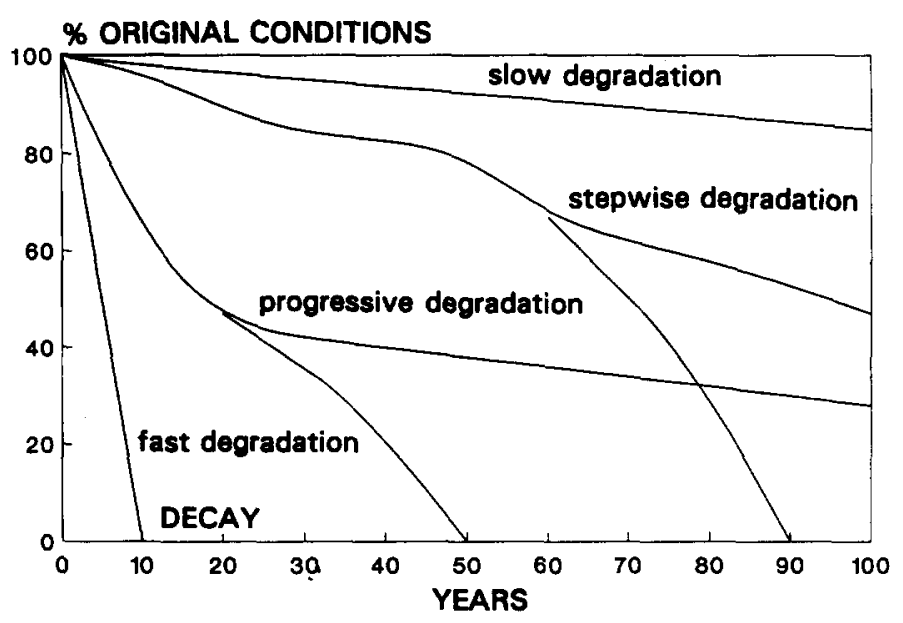

Fig. 1. Different paths of rock degradation according to Kühnel and Brych (1994). Different rocks show at different times constant or variable rates of degrading as compared with the original condition.

intimately intergrown mixture of these minerals usually replaces olivine. In older publications such multiphase mixtures were named "iddingsite". Recently, numerous other secondary minerals were identified in basalts including zeolites, serpentine minerals, vermiculite, carbonates, opal, silica polymorphs and many others.

Cooling of the deposited or intruded lava in a wet environment causes water uptake. The warmed up "hydrothermal" solutions promote further alteration of the rock constituents. Scanning electron microscope photomicrographs (Fig. 2a-c) demonstrate two major processes of dissolution of primary minerals and subsequent precipitation of secondary minerals in generated voids. Secondary minerals, including clay minerals, reflect the composition of migrating liquids and environmental conditions. The crystallization of clay minerals in tiny voids often generates high pore pressures, so that crystals of minerals show strong mechanical deformations that lead to the generation of microfissures (Fig. 3a-c).

Weathering processes, including the extended biosphere interaction, lead to the formation of the third and largest group of clay minerals. These are structurally and chemically similar to the previous ones. Although it is not always easy to recognize in which category a secondary mineral belongs, the mode of occurrence and interrelations with coexisting minerals gives some indication.

\section{Driving forces causing degradation and rock decay}

Two major driving forces contribute to rock degradation and decay: (1) inner strain which is caused by shrinkage during rapid cooling, and (2) phase transformations which are accompanied by volume changes. While the release of inner strain generates abundant microfissures which open ways for penetrating water and/or solutions, phase transformations accompanied by expansion widen these microfissures and generate other, more abundant microfissures and visible cracks as shown in Fig. 3a-c. In such a way, both driving forces weaken intergranular binding and subsequently reduce strength properties. 

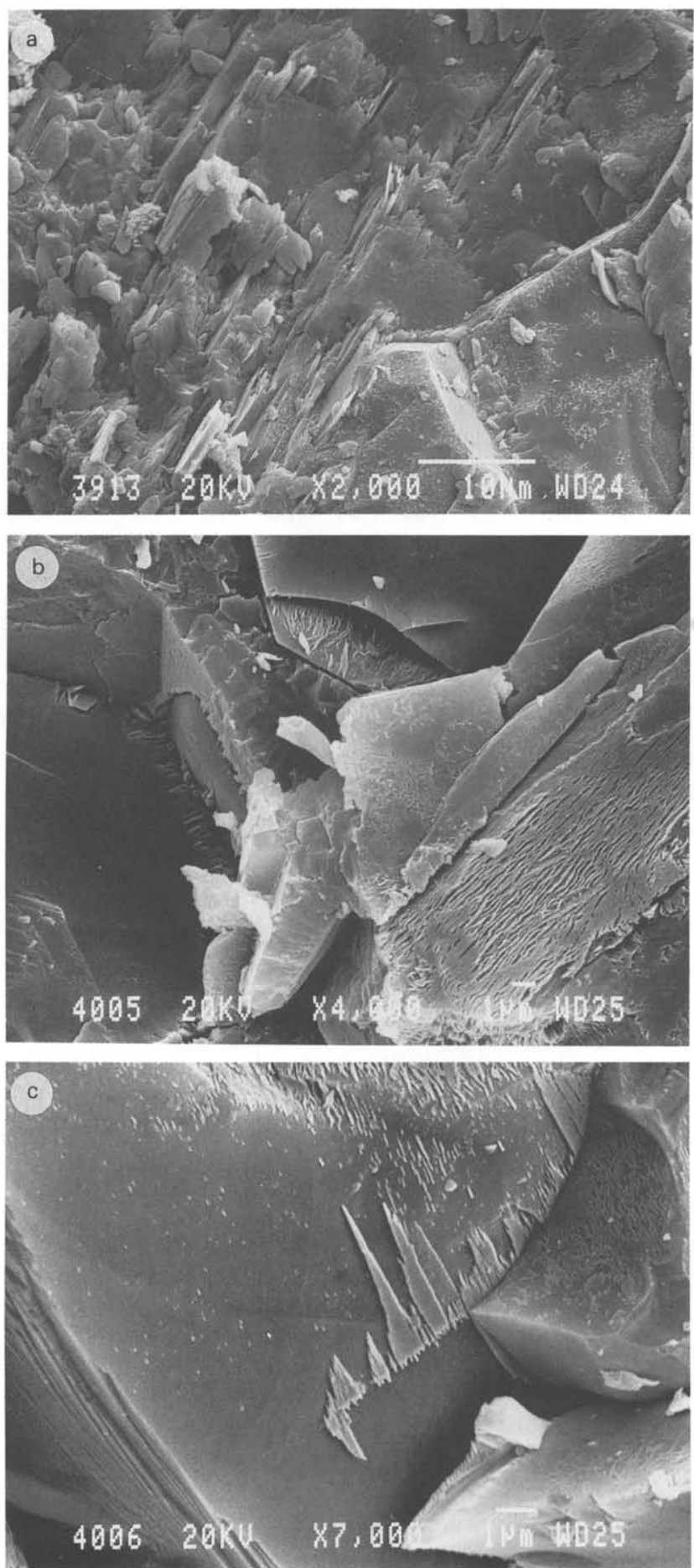

Fig. 2. Scanning electron microscope (SEM) photomicrographs $(a-c)$ showing general view and details of major phenomena ongoing during weathering: dissolution along and precipitation at fissures and expansion and loosening of intergranular binding. Spotty basalt. Germany. 

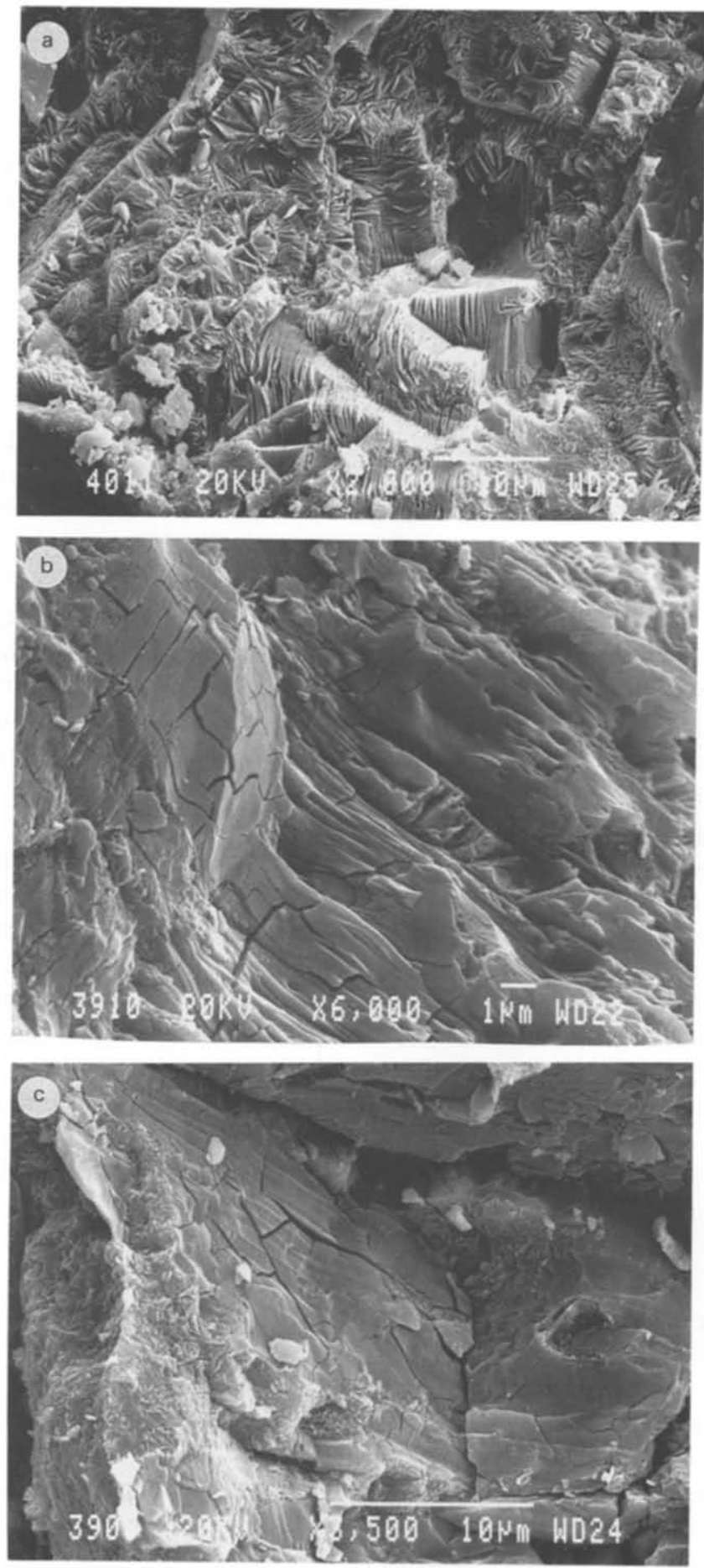

Fig. 3. Scanning electron microscope photomicrographs showing: (a) deformed crystals of clay minerals (chloritesmectite) growing under high pore pressure in fissures and voids in spotty basalt, and (b and $c$ ) network of fractures around spot enriched in swelling clay minerals. Spotty basalt. Germany. 
Both forces act simultaneously. In fresh rock the change of microfabric does not change the rock appearance. The effect of inner strain is more frequent in basaltic rocks with glass and is recognizable according to the undulose extinction and progressive glass replacement by secondary minerals. The change of the microfabric predetermines the rate of further weathering which is amplified close to the surface due to a stronger involvement of the biosphere.

\section{Visible symptoms of less durable basalts}

Since the beginning of the utilization of basalt as a construction material it is known that it develops a local "illness" called "sunburn" ("Sonnenbrand" in German) (see Ernst, 1960). The ageing of massive basalt, either on the surface or when in water, generates pale spots of 1-10 mm in size as shown in Fig. 4, and, star-like fractures which grow from the centre of some spots. Spots and fractures grow progressively and may become mutually interconnected. The basalt becomes paler and its mechanical properties are weakened. The rate of degradation varies according to the composition of the rock and its deposit site. Some basaltic rocks finally decay. On stockpiles and in abandoned quarries it has been possible to estimate the time of the degradation process as varying from months up to several years. In dikes which were constructed more than 100 years ago some columns of basalt have simply disappeared over time. On stockpiles in quarries it has been observed that $>6$ ton-blocks of basalt have disintegrated within several months into rubble.

On partially altered basalt surfaces the pale spots and star-like fractures are symptoms of less durable basalts. Fresh fracture planes of weaker basalts are rather irregular than conchoidal and smooth which occur usually on durable basalt. The difference in colour between wet and dry basalt is more distinct on less durable rocks because of fast formation of a thin film of alteration products. Finally, on surfaces of weaker basaltic rocks coatings of coloured clay minerals (greenish nontronite and bluish saponite) or whitish clay, carbonate and zeolite mixtures occur more frequently.

Generally speaking, glassy basaltic rocks and undersaturated rocks with feldspathoids and zeolites are more inclined to decay than saturated rocks. The durability of rocks is also indicated by the frequency of joints and natural parting planes, thickness of the soil profile, superficial rock degradation and its depth.

\section{Techniques for the recognition of invisible symptoms of less durable rocks}

Classical testing of mechanical properties of rocks is time consuming and expensive as it requires an accurate sample preparation and sophisticated testing machines. Moreover, it gives figures which represent a steady state situation. In order to follow the behaviour of the rock in time and/or under fluctuating conditions, the complex testing procedure should be repeated several times. However, the substitution of the long geological periods is difficult to simulate. Therefore the demand arises for testing of rocks by means of fast, cheap and reliable techniques. Similarly, a demand for techniques which can simulate very slow natural weathering processes within short periods arises. 


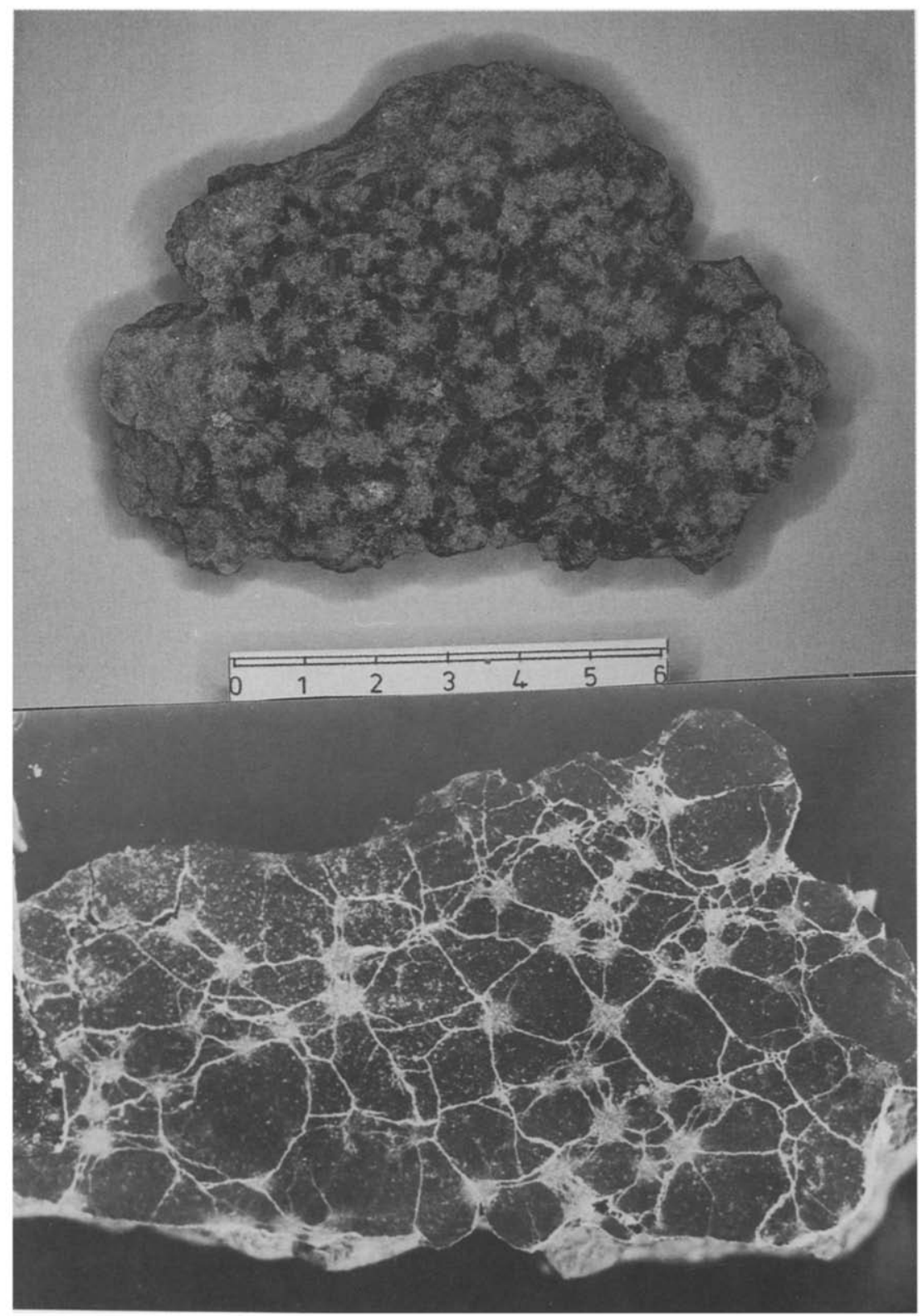

Fig. 4. Macroscopic view of degraded "spotty" basalt with a network of fractures resulting from boiling. The contrast is pronounced by filling of fractures with gypsum powder. Scale in $\mathrm{cm}$ is valid for both pictures. Basalt. Germany.

The boiling test is the oldest, simple technique which is still in use. By boiling fresh rock fragments for $36 \mathrm{~h}$ the process of spot and star-like fractures forming is accelerated. Boiling batches of $20-60$ rock fragments collected randomly after each blasting has become a 
common routine ( see Laan, 1985). Three per cent of weak (spotty after boiling) fragments is an arbitrary limit in the quality requirements.

The Methylene Blue (MB) absorption technique was recommended by Cole and Sandy (1980) for rating of basalt aggregate durability. The deleterious material in ground basaltic rocks include different clay minerals which, due to its fineness and particle charges, absorb more dye; the lower the MB absorption, the higher the durability.

There are many other techniques which are applied in research of durability of construction materials based on different principles; there are also trials to design deterioration models (see Bekker and Binda, 1992). According to many authors worldwide, the complex problem of durability of construction materials is not yet well understood. This study brings new information on clay minerals which induce different behaviour of basaltic rocks during the laboratory treatment.

Recently, several new techniques were designed by the authors as follows:

(1) Grinding and extraction test (Kühnel, 1985, 1990)

(2) Grinding in water (Kühnel and Van der Gaast, 1989)

(3) Rehydration of ground and dried basalt (Kühnel, 1994)

(4) Boiling and punching test (Kühnel and Brych in Cuper and Rijnsburger (1990))

(5) Treatment under extreme conditions and punching (Kühnel and Brych, 1994)

All these techniques demonstrate the role of clay minerals in rock durability. Each technique is sensitive either to the physical or chemical stability of rock-forming minerals, and often to both. Standardized grinding and extraction in two steps supply conductivities ( $\mu$ S-values) and $\mathrm{pH}$ values. Both values are considered for prediction of the chemical stability of the rock. Fig. 5 shows conductivity curves of different rocks and Fig. 6 shows the "envelopes" of conductivity curves obtained on a series of basalt samples from two different quarries; the narrower the "envelope", the more constant is the rock quality in the quarry.

Grinding basalt in water (and in cyclohexane for a comparison) leads to the formation of clay minerals and their precursors (X-ray amorphous substances). In the suspension derived from less durable basalts neoformed smectites and other clay minerals were found. Even a short term grinding of rocks in water (e.g. $1 \mathrm{~min}$ ) results in the formation of a quasiamorphous mixture of silicates and oxi-hydroxides. This mixture causes a significantly increased background on the XRD patterns. The sub-microscopical and colloidal particles interact with the water which have dissolved some ions from the ground silicates and other oxidic minerals. After a short time of ageing, clay minerals recrystallize from the precursor. Kühnel and Van der Gaast (1989) demonstrated a partial conversion of some constituents of basalts into smectites. Fig. 7 demonstrates a significant formation of $10 \AA$ micaceous clay mineral. For calculation of relative intensities, $1 \% \mathrm{MoS}_{2}$ internal standard has been used. Grinding rocks in water is actually a technique that simulates the natural weathering in an accelerated manner, though nevertheless in a closed system.

Rehydration of ground and dried rock sample is another technique which uses the diagnostic responses of clay minerals. When ground samples are exposed to humid air ( $>95 \%$ relative humidity) they often absorb water in much higher quantities than their original moisture content. Drying sample to successively higher temperatures results in higher water absorption when swelling clay minerals are involved. Kühnel (1994) explains this phenomenon as resulting from the of generation of numerous structural defects in fragile clay 
mineral crystallites due to drying. The resulting charge imbalance is subsequently compensated by $\left(\mathrm{H}_{3} \mathrm{O}\right)^{+}$absorption. In case of the less durable rocks, the water uptake progressively increases after repeated stepwise drying and rehydration of the same specimen to 100 and

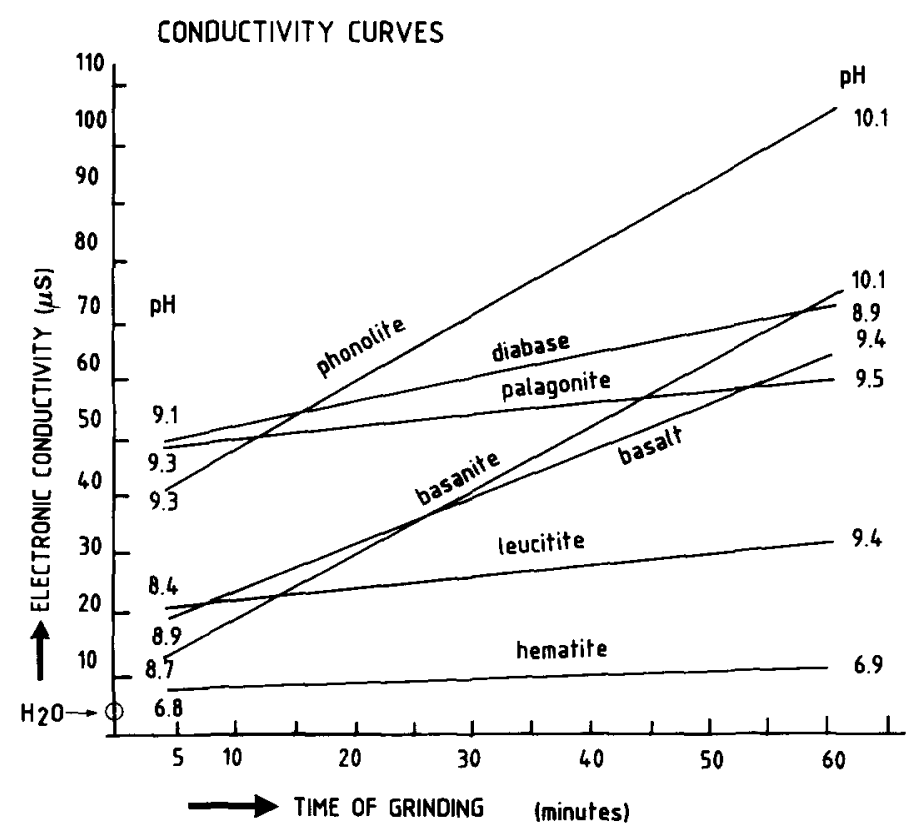

Fig. 5. Linear parts of the electric conductivity curves of extracts from ground rock. The electric conductivity of extracts (in micro-Siemens) grows linearly with the time of grinding in the range of 5-60 min. The pH-values of the extract are given for extracts after 5 and $60 \mathrm{~min}$ on the left and right, respectively. Less durable rocks (usually undersaturated) show higher conductivities and alkalinities.
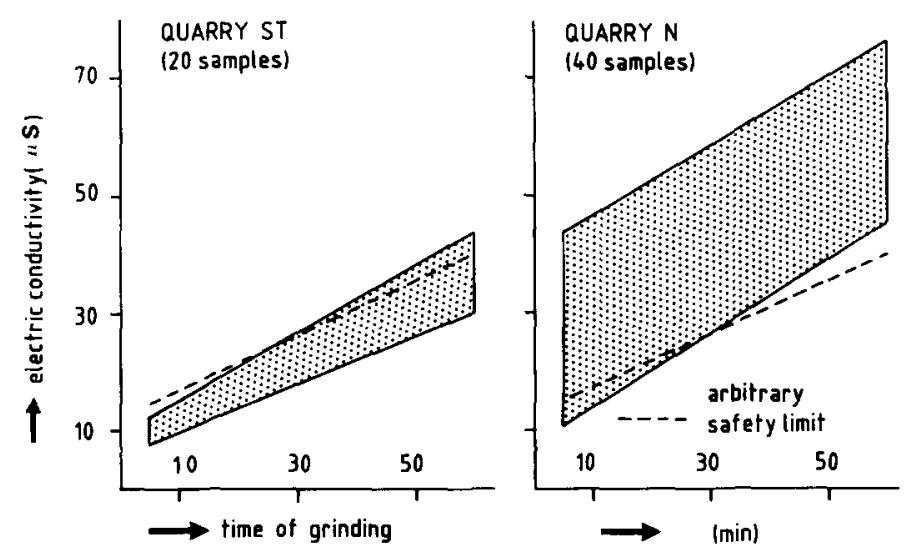

Fig. 6. An example of two "envelopes" which include electric conductivity curves of large numbers of basalt samples from two basalt quarries. The narrow "envelope" with lower conductivities indicate a quarry with more homogeneous and more durable material. 

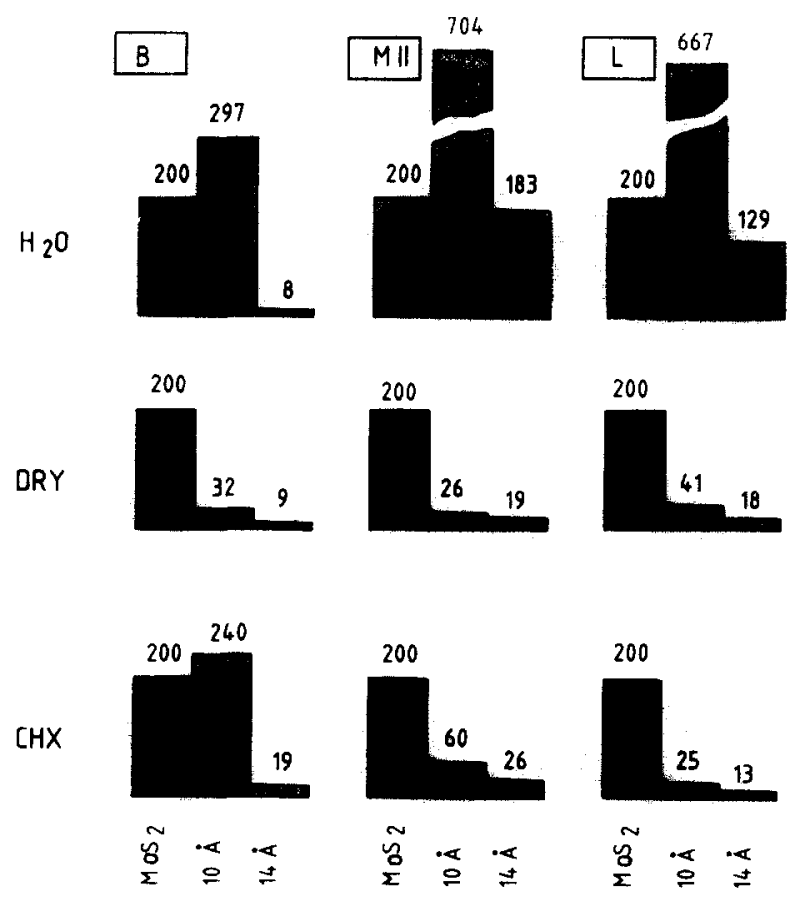

Fig. 7. Changes of intensities (in c/s) of 10 and $14 \AA$ clay minerals in three basalts (codes B, MIl, L): ground dry, in $\mathrm{H}_{2} \mathrm{O}$, and in cyclohexane ( $\mathrm{CHX}$ ). For measurement of intensities $1 \%$ of $\mathrm{MoS}_{2}$ internal standard was used and intensities were recalculated accordingly. In basalt B, $10 \AA$ clay mineral is formed when basalt is ground in water and in cyclohexane. In basalts MII and L both clay minerals ( 10 and $14 \AA$ ) were formed by grinding in water.

$200^{\circ} \mathrm{C}$. Fig. 8 shows the comparison of a durable (W) and less durable (BL) basalt sample. Recording water uptake is possible in a stepwise manner or by means of an adapted thermobalance. While the durable ground basalt (code W) absorbs, after heating to $200^{\circ} \mathrm{C}$, only approximately $5 \%$ more water in comparison with the air dried sample, the less durable basalt BL takes up close to $50 \%$ more water. The reason for this is a higher smectite content.

Brych designed in the mid eighties (see Brych et al., 1989) a new punching apparatus for the rapid testing of the mechanical properties of rocks. The principle is based on the Schreiner theory. Mechanical properties such as strength (resistance against a rod penetration), the Young's modulus and coefficient of plasticity are derived from the penetration/ punching of a tungsten carbide rod under increasing pressure up to the rupture when a conical "crater" is formed. This technique allows testing of small samples which are prepared as plates $25 \mathrm{~mm}$ thick with a surface $>10 \mathrm{~cm}^{2}$ of any shape. The technique is fully automated and computer aided. One test with graphical plots and complete calculation is ready in 3-5 min. Rock samples can be tested several times on the same surface, or on several samples with different orientation and after different treatment.

It was proven that boiling some rock samples leads to the depletion of strength of some rock samples. Measurement of a series of basalts before and after boiling was used for quantification of the rock durability as shown in Table 1. 

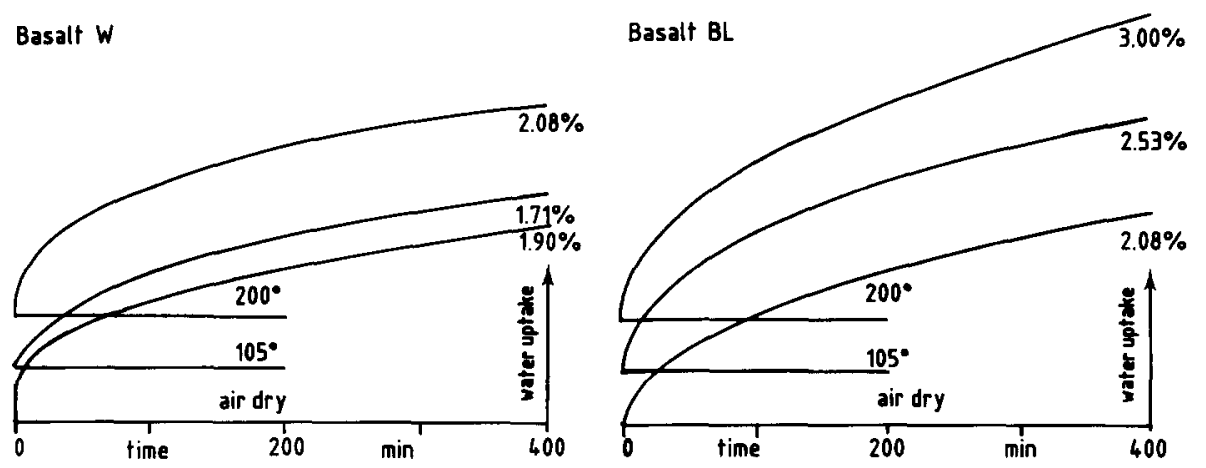

Fig. 8. Examples of rehydration curves measured on two ground basalt samples (codes W and BL) successively dried and rehydrated after cooling. Curves were obtained from an adapted thermobalance. One gram of the powdered $(-100 \mu \mathrm{m})$ air dried rock sample was placed on a sensitive balance and exposed to an atmosphere of $>95 \%$ relative humidity for $400 \mathrm{~min}$. The same sample was dried at $105^{\circ} \mathrm{C}$ and hydrated subsequently under similar conditions. Finally, the same sample was dried to $200^{\circ} \mathrm{C}$ and subsequently rehydrated. The identical air dried sample and samples dried to 105 and $200^{\circ} \mathrm{C}$ show different water uptake. To avoid overlapping, the rehydration curves are plotted separately, each with its own zero base line and shifted apart for an arbitrary interval. The rehydrated less durable basalt BL shows significant increase of uptaken water after heating due to the presence of swelling clay minerals.

Table 1

Degradation of some mechanical properties after boiling (in \% as compared to unaltered sample)

\begin{tabular}{lccc}
\hline Basalt code & Bending strength $^{\mathrm{a}}$ & $E$-modulus $^{\mathrm{a}}$ & Residual strength against punching $^{\mathrm{a}}$ \\
\hline MN & 104 & 101 & 111 \\
MY & 95 & 95 & 73 \\
BN & 21 & 13 & 103 \\
BY & 35 & 41 & 60 \\
WN & 101 & 0 & 18 \\
WY & 82 & 84 & 71 \\
STN & 54 & 20 & 2 \\
STY & 11 & 18 & 7 \\
NN & 28 & 4 & 2 \\
NY & 10 & 4 & 56 \\
HN & 4 & 0 & 103 \\
HN & 3 & 22 & 9 \\
BLN & 38 & 7 & 102 \\
BLY & 60 & 55 & 70 \\
\hline
\end{tabular}

${ }^{d}$ Data on bending strength and $E$-modulus according to Cuper and Rijnsburger (1990).

The degradation of less durable rocks is expressed as percentage of strength in comparison with untreated rock samples. Values $>100 \%$ indicate either a measuring error or an improvement of mechanical properties after boiling due to precipitation of $\mathrm{Mg}(\mathrm{OH})_{2}$, amorphous silica or other substances in voids, when temperature and $\mathrm{pH}$ change during drying. It is some kind of artificial "cementation" (reinforcement).

The new generation of testing techniques for the recognition of the durability of rocks uses a similar combination of treatment and testing. Up until now, ranking rocks according 
to their durability has expressed responses of rocks toward boiling. In order to further quantify the durability and rate of degradation a series of tests is ongoing by means of testing after treatment under extreme conditions (Kühnel and Brych, 1994).

The working idea is that a rock which better endures extreme conditions (e.g. attack of strong oxidants, glycolation, thermal shocks by heating and cooling under wet and dry conditions) will be also more durable under normal conditions. The utmost goal of research is to specify treatment which will estimate the probability of survival after servicing a specified period under given conditions. Because clay minerals are usually involved in rock decay, their detection and identification in minor quantities is essential.

\section{Conclusions}

(1) Even minor quantities of clay minerals in basalts strongly affect the rock durability. Clay minerals affect both physical and chemical stability of the rock. Their formation during weathering and/or laboratory treatment leads to the depletion of mechanical properties of rocks.

(2) Clay minerals in basalts are formed in different periods of the geological history of the rock. They are also formed during the treatment of massive and powdered samples in the laboratory. Clay minerals are formed due to rock-water interaction at the surface of the rock and along micro-fissures and fractures generated by the release of inner strain and/or by handling during quarrying. In addition, air and water polluted with aggressive compounds may locally amplify the rate of clay mineral formation.

(3) Clay minerals, particularly smectites are humidity sensitive. Their expansion and shrinkage due to wetting and drying lead to the weakening of intergranular bonds and may result in total rock decay.

(4) Several newly developed testing techniques contribute to a better understanding of the complex problem of basaltic rocks. The minor quantities of clay minerals in the original and treated samples allow prediction and quantification of the rock durability. No method is universal and only a combination of sensitive techniques accompanied by a comprehensive mineralogical characterization can result in an improvement of interpretation of existing testing results for particular basaltic rocks application.

\section{References}

Bain, D.C. and Russell, J.D., 1980. Swelling minerals in a basalt and its weathering products from Morvern, Scotland: I. Interstratified montmorillonite-vermiculite-illite. Clay Miner., 15: 445-451.

Bain, D.C. and Russell, J.D., 1981. Swelling Minerals in a Basalt and its Weathering Products from Morvern, Scotland: II. Swelling chlorite. Clay Miner., 16: 203-212.

Bain, D.C., Ritchie, P.F.S., Clark, D.R. and Duthie, D.M.L., 1980. Geochemistry and mineralogy of weathered basalt from Morvern, Scotland. Mineral. Mag., 43: 865-872.

Bekker, P. and Binda, L., 1992. Durability of masonry. Proc. International Workshop, Polytecnico of Milan, 2526 May, 1992.

Brych, J., Jadin, V., Ngoie Nsenga and Deschutter, R., 1989. Punching trial: complete and quick determination through a compact device. University of Mons. 
Cole, W.F. and Sandy, M.J., 1980. A proposed secondary mineral rating for basalt road aggregate durability. Austr. Road Res., 10(3): 27-37.

Cuper, H.J. and Rijnsburger, H.A., 1990. Untersuchung von Sonnenbrand bei Basalt. Report MAO-R-90008. Ministry of Transport, The Netherlands.

Eggleton, R.A., Foudoulis, Ch. and Varkevisser, D., 1987. Weathering of basalt: changes in rock chemistry and mineralogy. Clays Clay Miner., 35: 161-169.

Ernst, Th., 1960. Probleme des "Sonnenbrandes" basaltischer Gesteine. Z. Deutsch. Geol. Ges., 112: 178-182.

Kühnel, R.A., 1985. Development of a new technique for recognition of tendencies to rock decay. Report TUD, Delft University of Technology.

Kühnel, R.A., 1990. Ranking of basalt samples according to their chemical stability. Report TUD, Delft University of Technology.

Kühnel, R.A., 1994. Rehydration of powdered rocks as indicator of rock durability, in prep.

Kühnel, R.A. and Brych, J., 1994. Long term behaviour of basaltic rocks: some problems of testing under extreme conditions. University of Mons, Belgium, in prep.

Kühnel, R.A. and Van der Gaast, S.J., 1989. Formation of clay minerals by mechanochemical reactions during grinding of basalt under water. Appl. Clay Sci., 4: 295-305.

Laan, G.J., 1985. De betekenis van het verschijnsel zonnebrand voor de kwaliteit van basalt, toegepast in waterbouwkundige constructies. Report (in Dutch) DWW, Ministry of Transport, The Netherlands. 